\title{
CENTRALIZATION AND DECENTRALIZATION IN SUPPLY
}

\section{CHAIN MANAGEMENT}

\section{SHRISHAIL KANDI ${ }^{1}$, ANTRIKSH MUTHA ${ }^{2} \&$ A. B. KULKARNI ${ }^{3}$}

${ }^{1}$ Department of Mechanical Engineering, Vishwakarma Institute of Technology, Pune, Maharashtra, India

${ }^{2,3}$ Department of Mechanical Engineering, Jawaharlal Nehru Engineering College, Aurangabad, Maharashtra, India

\begin{abstract}
A supply chain is basically a network or an integrated process wherein several business entities work together and add certain kind of value to the raw materials which results into a finished product. Before reaching its final stage, the product undergoes various operations and correlating these operations involve developing a complex supply chain network. One major problem with complex supply chain network is the limited access of information of supply chain (as a whole), available to the individual decision makers. Each being responsible for the decisions taken for a certain part of supply chain. Every decision maker tries to operate under the presumption that optimizing their objective function would optimize the complete supply chain. However, it has been made known that greater efficiency can be attained by employing centralization technique. This paper aims at studying how centralization and decentralization affects a supply chain network.
\end{abstract}

KEYWORDS: SCM, Centralization, Decentralization \& Optimization

Received: Sep 20, 2017; Accepted: Oct 08, 2017; Published: Nov 06, 2017; Paper Id: IJIETDEC20172

\section{INTRODUCTION}

The supply chain consists of different work areas which can be arranged in series or parallel. The different work areas perform different processes on the raw material and these are then stored at intermediate storage systems. The finished product is finally stored in storage area in anticipation of future demands. Analyzing and organizing these operations can be done through either centralization or decentralization.

Centralization has a centralized structure with a central authority for decision making. This means that the power of planning and decision making is wholly in the hands of the top authority. Centralization is mainly preferred for small scale businesses or where the supply chain network isn't complicated.

Decentralization is a structure wherein the powers are disseminated from the main or the central authority to subordinate authorities. It is exactly opposite of centralization, in which the decision-making powers are delegated to the departmental, divisional, unit or center level managers, organization-wide.

Centralization approach is more suitable in taking strategic decisions whereas decentralization is more suitable in the domain of operations. 


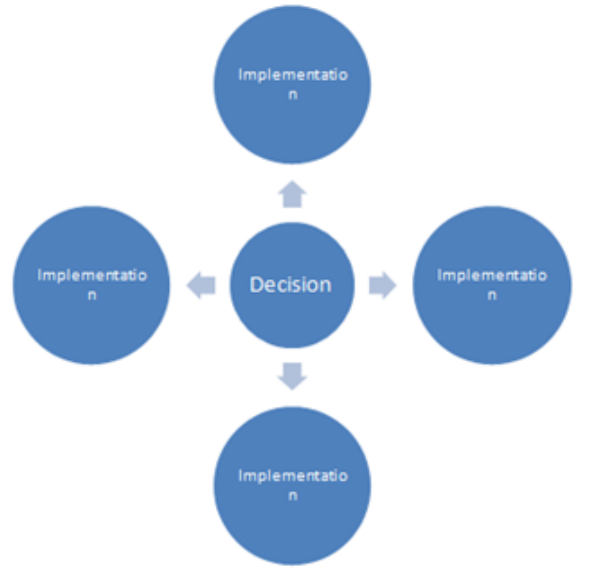

Centralization Approach

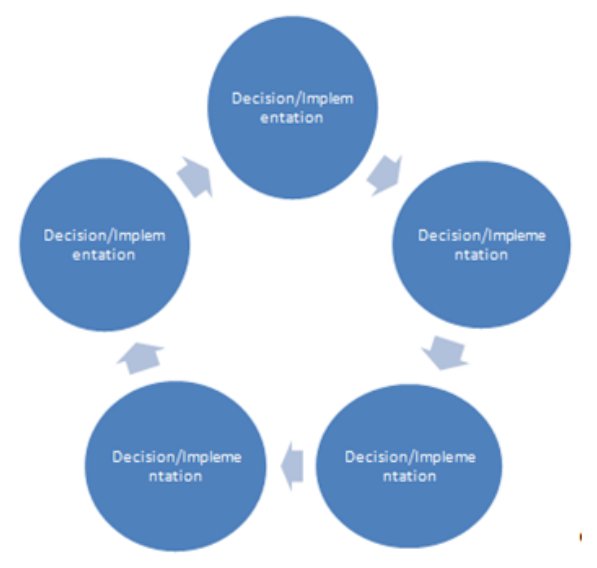

Decentralization Approach

\section{RESEARCH ELABORATIONS}

Benita M. Beamon defines supply chain, as a set of relationships among suppliers, manufacturers, distributors, and retailers that facilitates the transformation of raw materials, into final products. She further elucidates that, although the chain comprises of various numbers of businesses, but it is one single entity. Generally, practitioners and researchers have limited their analyses and scope to individual stages, within the larger chain.

Nihar Sahay, Marianthi Ierapetritou in " states that organizations often have, complex supply chains and operating them optimally, becomes a challenging task. Lack of collaboration among the different entities, including raw material suppliers, production sites, warehouses and retailers is one of the major problems, in managing supply chain networks. The problem is that, the different decision makers do not have access to the information, regarding the state of the entire SC network, and in addition they usually operate under different objective functions.

\section{RESEARCH OR FINDINGS}

\section{Optimization of Centralization and Decentralization}

Mathematically, the solution for problems of optimization of centralization and decentralization can be formulated in the form of two linear programs.

To form the mathematical models, as mentioned above, we take into consideration a given model, with three factories F1, F2 and F3, each connected in parallel with its respective vendor (vendors are the sub-contractors manufacturing the same component as the factory, used to supplant the factory's production when required), wherein the factories and vendors are considered as a single unit connected in series with other such units to form the supply chain.

\section{Optimizing Centralization}

In centralized model we take into consideration, the final production capacity of three factories, final demand, vendor costs, and inventory holding costs to optimize the overall operation cost of supply chain.

The objective function for the same is mathematically expressed in the following form:

$\operatorname{Min} \mathrm{Z}=\sum_{n=1}^{3}\left[c p_{n} \sum_{t=1}^{T} P_{n, t}+h_{n} \sum_{t=1}^{T} I_{n, t}+v_{n} \sum_{t=1}^{T} V_{n, t}\right.$

Subject to, 


$$
\begin{aligned}
& I_{1, t}=I_{1, t-1}+P_{1, t}+V_{1, t}-P_{2, t}-V_{2, t}, \forall t \\
& I_{2, t}=I_{2, t-1}+P_{2, t}+V_{2, t}-P_{3, t}-V_{3, t}, \forall t \\
& I_{3, t}=I_{3, t-1}+P_{3, t}+V_{3, t}-D, \forall t \\
& I_{1, t}=I_{2, t}=I_{3, t}=0 \\
& P_{n, t} \leq \rho_{n, t} \\
& P_{1, t}=P_{2, t}=P_{3, t}=0
\end{aligned}
$$

\section{Optimizing Decentralization}

In the decentralization process, the optimization is done individually for the three factories with optimization order as Factory 3-Factory 2-Factory 1.

For Factory No. 3

$\operatorname{Min} \mathrm{Z}=c p_{3} \sum_{t=1}^{T} P_{3, t}+h_{3} \sum_{t=1}^{T} I_{3, t}+v_{3} \sum_{t=1}^{T} V_{3, t}$

Subject to,

$$
\begin{aligned}
& I_{3, t}=I_{3, t-1}+P_{3, t}+V_{3, t}-D, \forall t \\
& I_{3, t}=0 \\
& P_{3, t} \leq \rho_{3, t} \\
& P_{3, t}=0
\end{aligned}
$$

For Factory No. 2

$\operatorname{Min} \mathrm{Z}=c p_{2} \sum_{t=1}^{T} P_{2, t}+h_{2} \sum_{t=1}^{T} I_{2, t}+v_{2} \sum_{t=1}^{T} V_{2, t}$

Subject to,

$$
\begin{aligned}
& I_{2, t}=I_{2, t-1}+P_{2, t}+V_{2, t}-P_{3, t}-V_{3, t}, \forall t \\
& I_{2, t}=0 \\
& P_{2, t} \leq \rho_{2, t} \\
& P_{2, t}=0
\end{aligned}
$$

For Factory No. 1

$\operatorname{Min} \mathrm{Z}=c p_{3} \sum_{t=1}^{T} P_{3, t}+h_{3} \sum_{t=1}^{T} I_{3, t}+v_{3} \sum_{t=1}^{T} V_{3, t}$

Subject to,

$$
\begin{aligned}
& I_{1, t}=I_{1, t-1}+P_{1, t}+V_{1, t}-P_{2, t}-V_{2, t}, \forall t \\
& I_{1, t}=0 \\
& P_{1, t} \leq \rho_{1, t}
\end{aligned}
$$


$P_{1, t}=0$

We can draw certain relations based on mathematical relations given above, they are as follows:

- After analysis of the linear mathematical formulations of centralized and decentralized approach we prove that systems cost of centralized optimization approach is less than or equal to the systems cost of decentralized optimization approach. We prove this assertion by Global and local minimum premise.

- The optimal solution for decentralized optimization is a feasible solution for centralized optimization but may not the optimal solution. That is, in terms of the optimal cost of individual factories, the minimum systems cost of factory 3 in case of decentralized optimization approach will be less than or equal to that of centralized optimization approach cost.

- For the combined systems cost of factory $2 \& 3$, a direct co-relation is formed from a. \& b. The systems cost of factory 3 ,in case of decentralized optimization approach, is less than or equal to centralized optimization approach, Therefore the combined systems cost in case of decentralized optimization approach of factory in $1 \& 2$ will be greater or equal to systems cost in case of centralized optimization approach.

\section{CONCLUSIONS}

After generating two linear mathematical formulations representing the two approaches of system cost optimization (centralization and decentralization optimization). We conclude that the centralized approach of optimization is more cost effective as compared to decentralized optimization approach, based on principle of local minima and global minima. Centralized approach gives us the global minimum optimized cost of the whole function whereas the decentralized approach gives a local minimum optimized cost for a part of the function.

\section{APPENDIX}

$T=$ Time Period (1 year)

$c p_{n}$ : Production cost of factory $F_{n}$,

$h_{n}$ : Inventory cost of factory $F_{n}$,

$v_{n}$ :Cost of vendor for factory $F_{n}$ during time period $t$,

$I_{n, t}:$ Inventory of factory $F_{n}$ during time period $t$,

$V_{n, t}:$ Vendor of factory $F_{n}$ during time period $t$,

$P_{n, t}:$ Production cost of factory $F_{n}$,

$\rho_{n, t}:$ Production capacity of factory $F_{n}$.

\section{ACKNOWLEDGMENT}

WE WOULD LIKE TO THANK DR. A. B. KULKARNI, FOR HIS RELENTLESS SUPPORT AND HELP IN WRITING THIS PAPER. WE WOULD ALSO LOVE TO THANK OUR PARENTS, FAMILY AND FRIENDS FOR SUPPORTING US IN OUR ENDEAVORS. 


\section{REFERENCES}

1. Benita M. Beamon, Supply Chain Design and Analysis: Models and Methods, International Journal of Production Economics (1998) Vol. 55, No. 3, pp. 281-294,http://citeseerx.ist.psu.edu/viewdoc/download?doi=10.1.1.129.9440\&rep=repl \&type=pdf

2. Nihar Sahay, Marianthi Ierapetritou, Centralized vs. Decentralized Supply Chain Management Optimization, 2013 AIChE Annual Meeting, November 3-8, 2013, Hilton San Fransisco Union Square, San Fransisco, CA, https://aiche.confex.com/aiche/2013/webprogram/Paper319958.html

3. Georgios K.D. Saharidis, Supply Chain Optimization: Centralized vs Decentralized Planning and Scheduling, https://cdn.intechopen.com/pdfs-wm/15529.pdf

4. Georges Sahardis, CENTRALIZED VERSUS DECENTRALIZED PRODUCTION PLANNING, http://citeseerx.ist.psu.edu/viewdoc/download;jsessionid=75FA93323A09546553DC008E3DD489F2?doi=10.1.1.537.8350\& $r$ ep $=$ rep 1 \& type $=p d f$ 
